http://jmscr.igmpublication.org/home/ ISSN (e)-2347-176x ISSN (p) 2455-0450

crossref DOI: https://dx.doi.org/10.18535/jmscr/v8i2.71

\title{
Smoking Cessation: A Study of Its Perioperative Benefits
}

\author{
Authors \\ Dr Sharath Kumar S*, Dr Chandrashekar N, Dr Naveen H Mahadev, \\ Dr Chandana Krishna, Dr Krishna Girish A V, Dr Varshith K \\ Sri Siddhartha Medical College Hospital \& Research Centre, Agalakote, Tumkur - 572107 \\ *Correspondence Author \\ Dr Sharath Kumar S \\ Junior Resident, Department Of General Surgery, SSMC, Tumkur
}

\begin{abstract}
Purpose: To find out the relation between smoking status and perioperative complications among the study subjects

Materials and Methods: 120 subjects were studied to determine the effect of smoking cessation on the incidence of perioperative complications.

Results: A total of 120 cases were studied from July 2017 to June 2019.

Conclusion: Cessation of Smoking in the perioperative period has shown to reduce the complications in the postoperative period even if the abstinence from Smoking is as late as 48 hours before the surgery to reduce cardiovascular complications and post-operative wound healing.

Keywords: Smoking, peri-operative complications.
\end{abstract}

\section{Introduction}

Tobacco smoking has been practiced by people all over the world, cutting across national and social barriers. Though Smokers have a substantially increased risk of intra and postoperative complications, which can be reduced by the cessation of smoking in the preoperative period. The preoperative period is a better time to offer smoking cessation interventions due to increased patient motivation $^{1}$

Many of the previous studies were conducted in patients who underwent thoracic surgery or taking various abdominal surgery procedures together. For example, patients who underwent Upper GI surgeries and hepatobiliary surgeries had double the risk of developing pulmonary complications compared to other surgical procedures ${ }^{2}$. Also, a random controlled trial evaluating abstinence from smoking two to three weeks before to colorectal surgery \& found no significant differences in complications seen in the post-operative period ${ }^{3}$. There are numerous works of literature suggesting smoking as a significant risk factor for complications in the postoperative period of various operations. Most common complications include surgical site infections \& pulmonary problems ${ }^{(4-7)}$

The benefits of short-term abstinence from smoking included an immediate reduction of nicotine levels \& carboxyhemoglobin in the blood. Benefits from the cessation of smoking for 48 hours before surgery include an expected 
reduction in cough, reduction in lower airway pathogens, decreases carboxyhemoglobin levels to normal range, abolished stimulant effects of nicotine on the cardiovascular system, and improved respiratory ciliary beating. In 2005, Moller A. conducted a research study that recommends smokers should abstain from smoking the morning of surgery, if not longer. because of the hemodynamic effects of smoking ${ }^{8}$ There are fewer studies to support the minimum abstinence period from smoking preoperatively. Hence for those patients who have failed to achieve a more extended period of smoking abstinence, this study was an assessment whether the cessation of the smoking intervention of at least $48 \mathrm{hrs}$ before surgery and in the postoperative period was effective in preventing postoperative complications

\section{Objectives}

1) To describe the perioperative complications among the study subjects.

2) To find out the association between smoking status and perioperative complications among the study subjects.

\section{Materials and Method}

The present study recruited male patients admitted to a tertiary health care centre, Tumkur, for elective abdominal operations. Chronic Smokers before surgery have explained the advantage of short term cessation of smoking preoperatively. Later we measure the period of abstinence from smoking in the pre and postoperatively. These patients were grouped into

a) Nonsmokers

b) Smokers

- Current smokers (who smoked within two weeks before the surgery) $)^{3,9}$

- Recent smokers (whose period of abstinence from smoking is 2- 4weeks before surgery $)^{3,9}$

- Ex-smokers (whose period of abstinence from smoking is > 4weeks before surgery) $)^{3,9}$ Current smokers were offered for smoking cessation intervention and those who agreed for cessation was considered in the short term abstinence group (48hours before surgery)

Patients were categorized according to pack-years and clinically evaluated for postoperative complications.

The total number of patients studied was 120. All the cases were evaluated by obtaining a detailed history and a thorough clinical examination. The findings were noted in a clinical proforma. Informed consent was obtained from every patient. Routine investigations like Complete Hemogram, Electrocardiography, and X-ray of the Chest were done to find out the disease-associated or any CI for surgeries. Other investigations like $\mathrm{C} \& \mathrm{~S}$ (Culture and Sensitivity) pulse oxy and Spirometry monitoring were done.

\section{Results}

A total of 120 cases were studied from July 2017 to June 2019.

Table 1: shows distribution according to Smoking status: In the present study, out of 120 patients, 66 $(55 \%)$ were smokers, and 54 (45\%) were nonsmokers. Among smokers, 45 patients are current smokers, 20 are ex-smokers, and 1 patient is a recent smoker. As all the current smokers agreed for cessation, all were included in the cessation group.

Table 2: shows distribution according to Pack years: 48 patients $(40 \%)$ belong to $0-5$ pack years group.10 patients $(8.3 \%)$ to $5-10$ pack years group, and 8 patients $(6.7 \%)$ to $>10$ pack years group.

\section{Diagnosis}

The maximum number of cases belonged to the inguinal hernia group $(76 ; 63.3 \%)$, and together with recurrent appendicitis, they constituted about $85 \%$. The remaining 18 cases include Paraumbilical hernia, epigastric hernia, GOO(Gastric outlet Obstruction) and cholelithiasis.

Incisions: For Inguinal Hernias, Lanz incision \& Grid-iron incisions together constitute about $75 \%$. 
Other incisions constitute $4 \%$ of midline incision, $4 \%$ of Paramedian incision, $2 \%$ of Kocher's incision, and $3 \%$ of supraumbilical and infraumbilical transverse incisions.

\section{Postoperative Complications}

Table 3: shows association between Postoperative Complications and Smoking. In the present study, $23(34.8 \%)$ smokers, and $4(5.6 \%)$, non-smokers developed postoperative complications. The smokers had 9times higher chance of complications compared to non-smokers (Odd's ratio $=9.09$ ).

Regarding age group, $17.2 \%$ of $20-30$ yrs, $13.6 \%$ of $31-40 \mathrm{yrs}, 26.7 \%$ of $41-50 \mathrm{yrs}, 16.7 \%$ of $51-60$ yrs, and $54.5 \%$ of $>60$ yrs developed postoperative complications.

According to smoking status, $40 \%$ of current smokers (smoking cessation group), and $20 \%$ of ex-smokers developed postoperative complications. The present study included one recent smoker who did not develop any postoperative complications.

Table 4: shows an association between Postoperative Complications and pack-years of Smoking. According to pack-years, $35.4 \%$ of 0 5 py, $40.0 \%$ of $5-10$ py. $37.5 \%$ of $>10$ py developed postop complications.

According to the type of anesthesia, $21.1 \%$ of SA, $25 \%$ of GA, $28.6 \%$ of LA developed complications. One surgery was performed under LA, and that patient developed a complication.

\section{Complications and Smoking status}

Current Smokers (Smoking cessation group): The majority of respiratory complications (9 out of 10) and all wound-related complications occurred in the smoking cessation group. 1 case developed CVS (cardiovascular) complication (especially hypertension) in our study belonging to the smoking cessation group. 9 cases in the smoking cessation group developed postoperative fever, and constipation forms another complication.
Ex-smokers and Recent Smoker: Respiratory complications are observed in 2 ex-smokers and postoperative fever is found in 2 patients. The present study included only 1 recent smoker, and no complications were seen in the postoperative period.

Non Smokers: 3 non-smokers developed postoperative complications, one being a respiratory complication, one fever, and one postoperative headache.

Table 5: shows the association between Overall postoperative Complications Among Smokers And Non-Smokers

- Wound complications occurred in 3 smokers and none in non-smokers.

- Respiratory complications occurred more in smokers than in non-smokers. OR-8.36, i.e., smokers had 8.36 times higher chance of developing respiratory complications compared to non-smokers.

- Hypertension was seen in a smoker and none in non-smokers.

- Fever occurred more in smokers than nonsmokers. OR-8.36, i.e., smokers had 8.36 times higher chance of developing fever compared to non-smokers.

- Overall, 16 smokers and 3 non-smokers had developed postoperative complications (QR- 9.09)

Complications and Pack years: Out of 3 woundrelated complications, one occurred in the 0-5 pack-year group and 2 in the 5-10 pack-year group. Respiratory complications were observed in 0-5 pack-year were 5 cases, in 5-10 pack year 3 cases, in $>10$ pack years 1 case $\&$ in non-smokers, only one case. 1 patient had developed CVS complications (hypertension) in the present study and he belonged to $>10$ pack-year groups. The majority of fever cases occurred in the 0 to 5 pack year group (7 of 9). Others were a case of constipation (0-5 pack-year) and a case of headache (non-smoker). 
Table 1: Distribution according to smoking status

\begin{tabular}{|l|c|c|}
\hline & Number of Patients & Percentage \\
\hline Non-Smoker & 54 & $45 \%$ \\
\hline Current Smoker & 45 & $37.5 \%$ \\
\hline Recent Smoker & 1 & $5.9 \%$ \\
\hline Ex-Smoker & 20 & $16.6 \%$ \\
\hline
\end{tabular}

Table 2: Distribution according to Pack years of Smoking

\begin{tabular}{|l|c|c|}
\hline Pack Years & Number of Patients $(\mathrm{N}=120)$ & Percentage \\
\hline $0-5$ pack-years & 48 & $40 \%$ \\
\hline 5-10 pack-years & 10 & $8.3 \%$ \\
\hline$>10$ pack-years & 8 & $6.7 \%$ \\
\hline
\end{tabular}

Table 3: Association between Postoperative Complications and Smoking.

\begin{tabular}{|l|c|c|c|}
\hline & Complications + & Complications - & OR \\
\hline Smokers & 23 & 43 & \multirow{2}{*}{9.09} \\
\hline Non Smokers & 3 & 51 & \\
\hline
\end{tabular}

Table 4: Association between Postoperative Complications and pack-years of Smoking

\begin{tabular}{|l|c|c|c|}
\hline Pack Years & Complications+ & Complications- & Total \\
\hline $0-5$ & 17 & 31 & 48 \\
\hline $5-10$ & 4 & 6 & 10 \\
\hline$>10$ & 3 & 5 & 8 \\
\hline
\end{tabular}

Table 5: Association between Overall postoperative Complications Among Smokers And Non-Smokers

\begin{tabular}{|l|c|c|c|}
\hline Complications & Smokers (66) & Non- Smokers (54) & Odd's Ratio \\
\hline Wound Related & 3 & 0 & \\
\hline Respiratory & 9 & 1 & 8.36 \\
\hline Hypertension & 1 & 0 & \\
\hline Fever & 9 & 1 & 8.36 \\
\hline Other & 1 & 1 & \\
\hline Total Patients Developing Complications & 23 & 3 & 9.09 \\
\hline
\end{tabular}

\section{Discussion}

Smoking abstinence during surgery will further motivate the patients for the cessation of smoking for a longer duration. The perioperative period can be considered as a 'teachable moment' for the cessation of smoking, \& patients can use this opportunity to restrain from smoking permanently. It will be a valuable benefit to their health.

Postoperative Complications: In the present study, 23 smokers and 3 non-smokers developed postoperative complications (OR 9.09).

Wound Related Complications: Poor and delayed wound healing is considered a significant side effect of smoking. Non Smokers were 3 times less likely to develop wound-related complications than smokers ${ }^{6}$. Smoking decreases $\mathrm{paO} 2$ by 22 -
$48 \%$, which causes chronic $\mathrm{O} 2$ deficiency in the peripheral tissue. $\mathrm{CO}$ will occupy binding sites of oxygen in hemoglobin molecule and the extent of this depends on the amount of tobacco consumed and time elapsed since last smoke. Carbon monoxide shifts the oxygen dissociation curve to the left, thereby causing reduced tissue oxygenation. Smokers also have a distinctly lowered production of collagen which is of great importance in wound healing ${ }^{7}$

Physicians may question, will short term preoperative smoking cessation improves the outcome of the patients. Even though many questions remain unanswered, there is good reason to believe that even brief abstinence may improve cardiac and wound-related outcomes. 
CO's shell life is about 4-6 hours. Hence 12-18 hours of the smoke-free interval should be there to lower the carboxyhemoglobin levels substantially. In the present study, wound related complications are seen in 2 patients, both the cases belonging to the Current smokers (2 out of 32.6.3\%). 1 belongs to the 0-5 packs year group, and another patient belongs to 5-10 packs year group. Study series done by Moller 2002, Lindstrom 2008, and Thomsen 2009, studied the incidence of postoperative complications among smokers. Our study is comparable with Lindstrom D et al. A higher incidence of postoperative complications is seen in all the study series.

Respiratory Complications: Cigarette smoking is a significant risk factor for postoperative pulmonary complications. This effect is primarily related to chronic lung disease, "Current cigarette smokers have an increased risk for PPCs even without chronic lung disease. Patients who smoke $>10$ cigarettes per day will have a 6 fold increase in the risk of developing respiratory morbidity. The responsible factors that include are small airway disease, hypersecretion of thick viscid mucus, and impairment of tracheobronchial clearance. The effects on immune function include decreased neutrophil activity, immunoglobulin concentration and natural killer activity. These effects take at least' 6 weeks of abstinence from smoking to return to normal ${ }^{8}$

Some physicians actually expressed concern that brief preoperative abstinence might be harmful. The results of some previous studies have been interpreted as showing that pulmonary complications are increased in the patients who give up smoking within the last few days or weeks before surgery. However, recent study results have shown that cessation within a few weeks of surgery doesn't significantly increase the rate of complications ${ }^{9}$. The present study total of 10 patients developed respiratory complications (7 current smokers, 2 ex-smokers, and 1 nonsmoker).V.I Cases observed in $>60$ years age group and V3 in 41-50 yrs age group. $43 \%$ of complications were found in the 5-10 pack years group. Compared to the other studies (Moller 2002, Lindstrom D 2003. Lindstrom D 2008, Lindstrom, 2008, and Thomsen, 2009). the present study is comparable with Lindstrom D 2003 (18.8\% and 16\% respectively). Moller 2002 and Lindstrom 2008 studies showed that there is a $2 \%$ decrease in the incidence, whereas Thomsen 2009 study result showed a $34 \%$ increase in the incidence.

Cardiovascular Effects: Smoking increases the risk of postoperative CVS complications. $\mathrm{CO}$ and nicotine are responsible for immediate cardiovascular effects ${ }^{10}$. CO formed by carboxyhemoglobin reduces the amount of hemoglobin available for combination with $\mathrm{O} 2$ and alters the oxygen dissociation curve, such that the affinity of the hemoglobin for oxygen is enhanced. It also has a weak ionotropic action on heart ${ }^{11}$. Nicotine being a neurotransmitter at sympathetic ganglia, increases heart rate, BP, and systemic vascular resistance. So, it enhances the demand for myocardium for oxygen while carbon monoxide decreases the supply. Elimination of both nicotine and $\mathrm{CO}$ with improvement in cardiovascular fitness is complete following 12 24 hour abstinence from smoking ${ }^{12}$.

In the present study, 1 patient developed CVS complication (i.e., hypertension), belonged to the current smoker, 51-60 yrs age group, and >10 packs year group. Compared to the other series (Moller 2002. Lindstrom D 2003, Lindstrom D 2008, and Thomsen 2009), this present study is comparable with Lindstrom 2008 and Thomsen 2009 studies (3.1\% and 2\% respectively). Moller 2002 study showed an increased incidence of $10 \%$.

\section{Overall Complications}

Smokers are at higher risk of complications than non-smokers in postoperative wound healing complications, as well as postoperative pulmonary and cardiovascular complications. 
$5-10 \%$ of the population may undergo surgery annually, and anesthesia-related lung or CVS complications are seen in $10 \%$ of the cases; people who smoke have a considerably increased risk of intra and postoperative complications ${ }^{13}$.

\section{Beneficial effects of smoking cessation for the various durations before surgery (Table: 3 )}

\begin{tabular}{|l|l|}
\hline Duration & Beneficial effects \\
\hline 12-24 hours & $\begin{array}{l}\text { Decreased carbon monoxide and nicotine } \\
\text { levels }\end{array}$ \\
\hline $48-72$ hours & $\begin{array}{l}\text { Carboxyhaemoglobin levels normalized. } \\
\text { Ciliary function improves }\end{array}$ \\
\hline 1-2 weeks & Decreased sputum production \\
\hline 4-6 weeks & Pulmonary function test improve \\
\hline $6-8$ weeks & $\begin{array}{l}\text { Immune function and metabolism } \\
\text { normalized }\end{array}$ \\
\hline 8-12 weeks & $\begin{array}{l}\text { Decreased overall postoperative morbidity } \\
\text { and mortality }\end{array}$ \\
\hline
\end{tabular}

To gain all the possible benefits with respect to perioperative morbidity, smoking should be stopped at least 6 weeks before surgery. Patients who find it very difficult to stop smoking for long durations will have some benefit in terms of improved CVS function even from a short period of abstinence (1.2-24 hours before their operation). Compared to the other studies (Moller 2002, Lindstrom D 2003, Lindstrom D 2000, Lindstrom 20013, and Thomsen 2009), in overall complications, the present study can be comparable with Lindstrom D 2003 and Lindstrom $20013 \quad(40 \%, \quad 3 \%$, and $41 \%$ respectively).

\section{Summary}

120 cases were studied. The mean age of the participants was found to be 40.04 years \pm 14.06 years. In our study, $39 \%$ of patients were current smokers, and non-smokers were $47 \%, 13 \%$ of patients belonged to ex-smokers, and $1 \%$ of patients belonged to recent smokers. $41 \%$ belongs to the 0-5 packs year group, $3 \%$ to 5-10 packs year group, and $4 \%$ to $>10$ pack years group. $75 \%$ of surgeries were clean, $3 \%$ are clean contaminated, and $22 \%$ contaminated surgeries. The majority of surgeries were done under SA
(86\%). Others include GA (5\%), epidural anesthesia (8\%), and local anesthesia (1\%).

$34.8 \%$ of smokers and $5.6 \%$ of non-smokers developed postoperative complications (Odd's ratio 9.09). 6.3\% of present smokers (cessation group) developed wound-related complications, $18.8 \%$ developed respiratory complications, $3.1 \%$ developed cardiovascular complications, and $21.9 \%$ developed a postoperative fever. Overall, $40 \%$ of present smokers developed postoperative complications.

Compared to other studies, current smokers with short- term preoperative smoking cessation (48 hours before surgery) derived seine benefit regarding cardiovascular and wound-related outcomes.

\section{Conclusion}

- Non-smokers are at a lesser risk than smokers in postoperative complications.

- Awareness regarding the harmful effects of smoking and its influence on post-op wound healing, motivation for quitting, and abstinence from smoking will help in reducing post-op complications and better treatment outcomes.

\section{Acknowledgment: Nil \\ Financial support: Nil}

\section{References}

1. Moller A, Villebro N. Interventions for preoperative smoking cessation. Cochrane Database of Systematic Reviews 2005, Issue 3 , Art.No:CD002294.DOI: 10.1002n4651858.CD002294.pub

2. Scholes RL, Browning L, Sztendur EM, Denehy L. Duration of anesthesia, type of surgery, respiratory co-morbidity, predicted VO2max, and smoking predicts postoperative pulmonary complications after upper abdominal surgery: an observational study. Aust J Physiother. 2009;55(3):191198.doi:10.1016/S0004-9514(09)70081-9. 
3. Sorensen LT, Jorgensen T. Short term preoperative smoking cessation intervention does not affect postoperative complications in colorectal surgery: a randomized clinical trial: Colorectal Dis 2003;5(4):347-52.

4. Hawn MT, Houston TK, Campagna EJ, Graham LA, Singh J, Bishop M, Henderson WG. The attributable risk of smoking on surgical complications. Ann Surg. 2011; 254(6):914-920.

DOI: 10.1097/SLA.0b013e31822d7f81. [PubMed] [CrossRef] [Google Scholar]

5. Gajdos C, Hawn MT, Campagna EJ, Henderson WG, Singh JA, Houston T. Adverse effects of smoking on postoperative outcomes in cancer patients. Ann Surg Oncol. 2012; 19(5):1430-1438. DOI: 10.1245/s10434-011-2128-y. [PMC free article] [PubMed] [CrossRef] [Google Scholar]

6. Toyoda Y, Fu RH, Li L, Otterburn DM, Rohde CH. Smoking as an independent risk factor for postoperative complications in plastic surgical procedures: a propensity score-matched analysis of 36,454 patients from the NSQIP database from 2005 to 2014. Plast Reconstr Surg. 2018; 141(1):226236.

DOI: 10.1097/PRS.0000000000003963. [PubMed] [CrossRef] [Google Scholar]

7. Atilla N, Arpag H, Bozkus F, Kahraman H, Cengiz E, Bulbuloglu E, Atilla S. Can we predict the perioperative pulmonary complications before laparoscopic sleeve gastrectomy: original research. Obes Surg. 2017;27(6):1524-1528. DOI: 10.1007/s11695-016-2522-4. [PubMed]

[CrossRef] [Google Scholar]

8. Lauerman, Cecelia J. Surgical patient education related to smoking. AORN Journal:2008 Mar 1. [Cited 2008 Jun 17]; Available from http://goliath.eciiext.com'coms2': summary 01997651248 ITM.
9. Chandrashekar N, Prabhakara G.N, Shivakumarappa G.M, Venkatesh N, Adithya Rangarajan "Study of Smoking cessation and its intra and postoperative benefits."Journal of Evolution of Medical and Dental Sciences 2013; Vol. 2, Issue 51, December 23; Page: 10020-10027.

10. Dr.Rudra A, Dr. Sudipta Das. Postoperative pulmonary complications. Indian Journal of Anaesthesia; 2006;50(2):89-98.

11. Lindstrom I). A/od; OS. Wladis A. Tonncsen II. I inder S, NJasell 11 et al. Effects of a perioperative smoking cessation intervention on postoperative complications-a random/cd trial. Annals of Surgery 2008(5):739-45.

12. Thomsen T. Tonnesen H. Moller AM.Effect of preoperative smoking cessation interventions on postoperative complication and smoking cessation British Journal of Surgery.2009:96:45 I-61.

13. Nimmo WS. Rowbotham DJ. Smith G editors.anesthesia.2nd cd. Oxford: Blackwell Scientific Publications; 1989. vol 2. PI 193-4, 1201.

14. Stocking RK, Dierdorf SI editors. Anesthesia and co-existing diseases.4th cd. New Delhi: Harcourt (India) Private Limited: 2002. pi78. 184-6.

15. Cashier SA, Steele RJC, Moossa AR editors. Essential surgical practice, basic surgical training.4th ed.London: Arnold, Hodder Headline group: 2001.p71.

16. Hams S, Arora S.editors. Stop before the Opproposals to adopt a preoperative smoking cessation policy. Proceedings of the Board meeting of GPC1 2007 Sep 26: Gloucestershire: UK.

17. Bajaj P. Preoperative smoking cessation. Indian Journal of Anaesthesia 2008:52(2): 123-5. 